\title{
Carbon Dioxide Monitor Subassembly Device
}

National Cancer Institute

\section{Source}

National Cancer Institute. Carbon Dioxide Monitor Subassembly Device. NCI Thesaurus.

Code C49875.

A carbon dioxide monitor assembly designed to be part of another device. 